\title{
Improved biological properties and hypouricemic effects of uricase from Candida utilis loaded in novel alkaline enzymosomes
}

This article was published in the following Dove Press journal:

International Journal of Nanomedicine

20 July 2012

Number of times this article has been viewed

\author{
Qun-You Tan',* \\ Jing-Qing Zhang ${ }^{2, *}$ \\ Na Wang ${ }^{3, *}$ \\ Hong Yang ${ }^{4}$ \\ Xiaoling $\mathrm{Li}^{5}$ \\ Hua-Rong Xiong ${ }^{2}$ \\ Jian-Yong $\mathrm{Wu}^{2}$ \\ Chun-Jing Zhao ${ }^{3}$ \\ Hong Wang ${ }^{2}$ \\ Hua-Feng Yin ${ }^{2}$
}

'Department of Thoracic Surgery, Institute of Surgery Research, Daping Hospital, Third Military Medical University, Chongqing, ${ }^{2}$ Medicine Engineering Research Center, Chongqing Key Laboratory of Biochemical \& Molecular Pharmacology, Chongqing Medical University, Chongqing, ${ }^{3}$ School of Pharmacy, Second Affiliated Hospital, Chongqing Medical University, Chongqing, ${ }^{4}$ School of Pharmacy, Medical College of Soochow University, Soochow, People's Republic of China; ${ }^{5}$ TJ Long School of Pharmacy and Health Sciences, University of the Pacific, Stockton, CA, USA

*These authors contributed equally to this work
Correspondence: Jing-Qing Zhang Chongqing Key Laboratory of Biochemical \& Molecular Pharmacology, Medicine Engineering Research Center, Chongaing Medical University, 50I, Building 22, Jingdi Garden, 6 Dahuang Road, Yuzhong District, Chongqing 400042,

People's Republic of China

Tel $+86 \quad 13308300303$

Fax +86 2368767988

Email zjqrae0I@163.com
Objective: Previous studies on various enzymosomes (functional lipid vesicles encapsulating an enzyme) have been mostly carried out in vitro and have focused on preserving catalytic activity and improving the stability of the enzyme. Until now, few studies have focused on their in vivo fate. Similarly, although we have previously reported the increased in vitro uricolytic activity (about 2.2 times higher than that of free uricase, or three times higher than that of PEGylated uricase, Puricase ${ }^{\circledR}$, under physiological $\mathrm{pH}$ and temperature) and improved stability of the novel alkaline enzymosomes (functional lipid vesicles encapsulating uricase from Candida utilis: uricase-containing lipid vesicles, UOXLVs), it is still necessary to study the biological properties and hypouricemic effects of UOXLVs in vivo.

Methods: The enzyme kinetics, pharmacokinetics, pharmacodynamics, immunogenicity, and preliminary safety of UOXLVs were evaluated.

Results: The Michaelis constant $\left(\mathrm{K}_{\mathrm{m}}\right)$ value of the UOXLVs was slightly lower than that of the free enzyme. The enzyme release from the UOXLVs lasted over 12 hours and their circulation half-life was about sevenfold longer than that of the free uricase. Meanwhile, the UOXLVs had a 22-fold increase in the area under the curve compared with the free uricase. Furthermore, it took less than 3 hours for the UOXLVs to lower the plasma uric acid concentration from a high to a normal level, compared with 6 hours for the free uricase. In addition, the UOXLVs had much less immunogenicity than free uricase and were well tolerated by all animals throughout the observation period.

Conclusion: The UOXLVs markedly improved the biological properties and enhanced the hypouricemic effects of uricase in vivo.

Keywords: biological properties, hypouricemic effect, uricase, alkaline enzymosomes, in vivo

\section{Introduction}

Enzymes are promising therapeutic agents due to their specific substrate selectivity and unparalleled reaction efficiency. Moreover, the intrinsic shortcomings of enzymes, such as relatively low enzymatic activity under physiological conditions, short circulation life, and inherent immunogenicity, might be overcome by encapsulating them into certain biocompatible and biodegradable drug carriers, such as lipid vesicles.

Uricase (EC 1.7.3.3, urate oxidase [UOX]) is a typical example of an enzyme which can be used therapeutically. Uricase can catalyze the oxidation of uric acid into allantoin, a product that is more soluble and readily excreted by the kidney. ${ }^{1}$ Uricase occurs widely in nature but not in humans due to a mutation of the uricase gene during evolution. Therefore, uricase from various microorganisms has been intravenously administered for nearly 40 years to treat hyperuricemia and gout. ${ }^{2}$ However, the 
clinical application of uricase has been limited due to its undesirable biological properties (ie, premature degradation and inactivation by endogenous proteases, elimination by the reticuloendothelial system, immunogenicity, and toxic side effects caused by the host immune system reacting toward foreign proteins). ${ }^{3}$ To overcome these enzymatic problems, a variety of uricase preparations, such as polyethylene glycol (PEG) uricase, ${ }^{4}$ alginate-microencapsulated uricase, ${ }^{5}$ dextranPEG-coupled uricase, ${ }^{6}$ and erythrocyte-encapsulated uricase ${ }^{7}$ have been developed. Nevertheless, these vesicles have some shortcomings, such as enzyme deactivation during immobilization reactions, the physical instability of the carriers when oxygen bubbles are produced, and the readiness of the uricase to fall off the vesicles.

The lipid vesicle is probably a more favorable carrier for the enzyme than the vesicles mentioned above. In 1970, Sessa and Weissmann ${ }^{8}$ wrote the first paper on entrapping an enzyme in a lipid vesicle. Over the last four decades, the biomedical field has focused on applying enzyme-containing lipid vesicles to enzyme-replacement therapy., ${ }^{910}$ The enzyme reactions occurring in lipid vesicles have received considerable attention because the stability and activity of the lipid vesicle enzyme are potentially regulated by keeping an intact molecular structure of the enzyme. ${ }^{11-14}$ Previous studies have suggested that lipid vesicles, including uricase, might be an effective delivery system for the enzyme. ${ }^{14,15}$

However, previous studies on this topic have only been carried out in vitro and have focused on improving stability and preserving the catalytic activity of the enzyme. ${ }^{10,14,15}$ Until now, few studies have been conducted on the in vivo fate of lipid vesicles loaded with enzymes. Insufficient understanding of the in vivo behavior of enzyme-containing vesicles greatly restricts their applications. The quantitative analysis of experimental data on the pharmacokinetics of enzymecontaining vesicles and the entire theoretical and practical treatment of enzyme-containing lipid vesicles thus requires further attention.

Therefore, we designed and prepared novel alkaline enzymosomes (functional lipid vesicles encapsulating the therapeutically active enzyme of uricase: uricase-containing lipid vesicles, UOXLVs) with desired in vitro characteristics (Figure 1). The aim of this study was to explore and evaluate the biological properties and enhanced hypouricemic effects of UOXLVs, including their pharmacokinetics, pharmacodynamics, immunogenicity, and preliminary safety. Prolonged plasma circulation, improved therapeutic efficacy, and reduced immunogenicity of UOXLVs were demonstrated. Our findings indicate that the biological properties and the

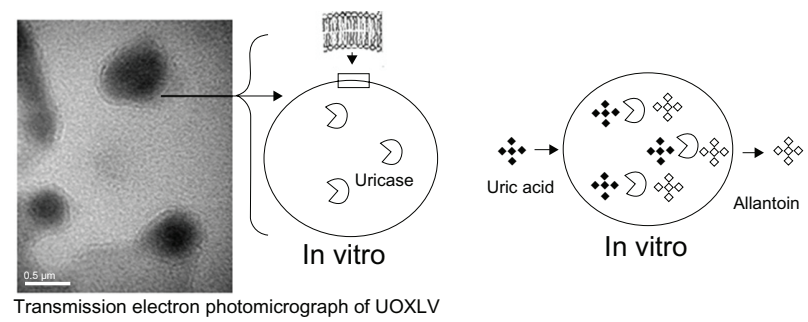

Figure I Schematic diagram of uricase-containing lipid vesicles (UOXLVs) catalyzing the transformation of uric acid into allantoin.

hypouricemic effect of uricase from Candida utilis would be noticeably improved by loading it into novel alkaline enzymosomes.

\section{Materials and methods Materials}

Uricase from the C. utilis species (activity of 3.2 units $/ \mathrm{mg}$ powder at $25^{\circ} \mathrm{C}$ ) and bovine plasma albumin were obtained from Sigma-Aldrich (St Louis, MO). Hydrogenated soybean phosphatidylcholine was obtained from Lucas Meyer GmbH (Hamburg, Germany). Cholesterol, an imported product, was obtained from Tianma Fine Chemical Plant (Guangzhou, China). Sephadex ${ }^{\mathrm{TM}} \mathrm{G}-200$ was obtained from Kaixiang Biotechnology Co, Ltd (Shanghai, China). Goat anti-rat immunoglobulin $\mathrm{G}(\mathrm{IgG})(\mathrm{H}+\mathrm{L})$ /horseradish peroxidase (HRP) was obtained from Zhongshan Goldbridge Biotechnology Co (Beijing, China). Ortho-phenylenediamine was obtained from Amresco Inc (Solon, $\mathrm{OH}$ ). All other reagents and solvents used in the study were of analytical grade.

\section{Animals}

Male Sprague Dawley rats weighing 250-300 g were chosen for study as specific pathogen-free animals. These animals were obtained from the Laboratory Animal Center of Chongqing Medical University, Chongqing, China. The animals were housed under standard laboratory conditions. All studies were performed in accordance with the protocol approved by the Laboratory Animal Committee, Chongqing Medical University.

\section{Methods}

\section{Preparation and characteristics of UOXLVs}

UOXLVs were prepared using the reverse-phase evaporation method as described previously. ${ }^{16}$ Briefly, hydrogenated soybean phosphatidylcholine and cholesterol (molar ratio of 1:1) were dissolved in $30 \mathrm{~mL}$ of chloroform. The chloroform was removed by rotary evaporation, and the lipid film obtained was redissolved in $30 \mathrm{~mL}$ of diethyl 
ether. The organic phase was then added to $10 \mathrm{~mL}$ of $50 \mathrm{mmol} / \mathrm{L}$ borate buffer, $\mathrm{pH} 8.5$, containing $16.7 \mathrm{nmol} / \mathrm{L}$ uricase and $14.7 \mathrm{nmol} / \mathrm{L}$ bovine plasma albumin. The two-phase system was sonicated in a bath sonicator until the mixture became a stable and homogeneous opalescent dispersion. Next, the mixture was placed in a rotary evaporator and diethyl ether was removed under reduced pressure. As the majority of the diethyl ether evaporated, the material formed a viscous gel, which collapsed into a lipid-in-water suspension. Following this, another $10 \mathrm{~mL}$ of the borate buffer was added, and the mixture was rotated for an additional 30 minutes to remove all traces of the solvent.

The size of the uricase-containing lipid vesicles was homogenized by passing the sample through a $0.22 \mu \mathrm{m}$ mixed cellulose filter. The average diameter and the polydispersity index of the UOXLVs were determined by photon correlation spectroscopy using a Malvern Zetasizer Nano ZS90 (Malvern Instruments Ltd, Worcestershire, UK) and the zeta potential was determined with the same device. The UOXLVs were separated from the free uricase by gelexclusion chromatography performed with a $15 \times 400 \mathrm{~mm}$ Sephadex G-200 column. ${ }^{17}$ The Coomassie blue method was used to determine the protein content. ${ }^{18}$ Next, the percentage of entrapment was calculated. ${ }^{19}$ The effect of temperature on the UOXLVs and free uricase was investigated in the temperature range of $20^{\circ} \mathrm{C}-70^{\circ} \mathrm{C}$, and the effect of $\mathrm{pH}$ on the UOXLVs and free uricase was investigated in the $\mathrm{pH}$ range of 6.5-9.5 in borate buffers.

\section{Measurement of uricase activity}

The uricase activity was assayed by a patented kinetic uricase method $^{20}$ and measured with uric acid as a substrate. Briefly, $20 \mu \mathrm{L}$ of uricase solution was added to the borate buffer solution containing $75 \mu \mathrm{mol} / \mathrm{L}$ of uric acid. Next, the time course of the uric acid's decomposition was determined based on the absorbance of the uric acid at $293 \mathrm{~nm}$ with the molar extinction coefficient of $\varepsilon_{293 \mathrm{~nm}}=11.5 \mathrm{~mol} / \mathrm{L} / \mathrm{cm}$ using a spectrophotometer. The enzyme activity was expressed in $\mathrm{U} / \mathrm{mL}$ and $1 \mathrm{U} / \mathrm{mL}$ was defined as the amount of uricase that was able to catalyze the oxidization of $1 \mu \mathrm{mol} / \mathrm{L}$ of uric acid into allantoin per minute at $25^{\circ} \mathrm{C}$.

\section{Enzyme kinetic study}

Experiments for kinetic parameter estimation were performed by catalyzing the oxidation of uric acid solutions at varying concentrations $(10-50 \mu \mathrm{mol} / \mathrm{L})$ at $25^{\circ} \mathrm{C}$ in a water bath incubator. The reaction medium contained $0.1 \mathrm{mg} / \mathrm{Ml}^{-1}$ of free or entrapped uricase. Uric acid solutions were prepared in $50 \mathrm{mmol} / \mathrm{L}$ borate buffer ( $\mathrm{pH} 8.5$ ). Enzyme activity was assayed as described. Each experiment was conducted in triplicate. The initial rates were calculated using the linear portion of the substrate versus time plot, then the enzyme kinetic parameters were calculated by Lineweaver-Burk plotting (Equation 1).

$$
\frac{1}{V}=\frac{K_{m}}{V_{\max }} \cdot \frac{1}{[S]}+\frac{1}{V_{\max }},
$$

where $V$ is the reaction velocity, $[S]$ is the substrate concentration, $K_{m}$ is the Michaelis constant, and $V_{\max }$ is the maximum velocity.

\section{Stability of UOXLVs in the presence of plasma}

The same amounts of uricase in $1 \mathrm{~mL}$ of UOXLVs and free uricase solution were added to $5 \mathrm{~mL}$ of rabbit plasma. The temperature of the mixture was measured at $37^{\circ} \mathrm{C} \pm 0.5^{\circ} \mathrm{C}$ and shaken at $42 \pm 3 \mathrm{rpm}$. Aliquots were taken at various time intervals and the activity of the uricase was measured.

\section{Pharmacokinetic study}

The Institutional Animal Care and Use Committee of Chongqing Medical University approved all experiments in this study. Using a single-dose, randomized, openlabel, two-period crossover trial design, six male Sprague Dawley rats (weighing 250-300 g) in each group were intravenously administered with uricase $(2000 \mathrm{mU} / \mathrm{kg})$ and UOXLVs (2000 mU/kg), respectively. Blood samples were drawn from the posterior orbital venous plexus at various times $(0.017,0.25,0.5$, and 1 hour and at 2,4 , 6,8 , and 12 hours) and immediately centrifuged at 3000 rpm for 10 minutes. The plasma samples were stored at $-20^{\circ} \mathrm{C}$ until analysis.

The concentration of uricase in the plasma was evaluated by enzymatic activity. ${ }^{6}$ The uricase activity was measured with uric acid as a substrate using the patented kinetic uricase method described. ${ }^{20}$ The pharmacokinetic parameters were estimated by statistical moment analysis. ${ }^{21}$ DAS for Windows software (v 2.1.1; Mathematical Pharmacology Professional Committee of China, Shanghai, China) was utilized to analyze the pharmacokinetic parameters of the area under the plasma concentration-time curve, apparent volume of distribution, body clearance, half-life, and mean residence time (MRT) of the uricase for each formulation. 


\section{Pharmacodynamic study}

Establishment of the hyperuricemia rat model

Male Sprague Dawley rats (weighing 250-300 g) were intragastrically administered $500 \mathrm{mg} / \mathrm{kg}$ of hypoxanthine in a 3\% soluble starch solution and $100 \mathrm{mg} / \mathrm{kg}$ of oxonic acid potassium salt in a mixed solvent of lanolin-liquid paraffin (volume ratio of 3:2) subcutaneously. In this hyperuricemia rat model, the plasma uric acid level elevated quickly and lasted for more than 12 hours (the mean uric acid level was determined in hyperuricemia rats within 24 hours and was $343.94 \mu \mathrm{mol} / \mathrm{L}$, $\mathrm{n}=30$ ). In contrast, the rats in the negative control group were given the same volume in a $3 \%$ soluble starch solution and a mixed solvent of lanolin-liquid paraffin (volume ratio of 3:2). The mean uric acid level was determined in the normal rats within 12 hours and was $130.02 \mu \mathrm{mol} / \mathrm{L}(\mathrm{n}=30)$.

\section{Pharmacodynamic study}

Four groups of rats (six rats per group) were used to determine the pharmacological efficacy of the uricase formulations as follows: (1) normal rat group (negative control group); (2) the hyperuricemia rat model group, without treatment (positive control group); (3) the free uricase group; and (4) the UOXLVs group. The rats in Groups 3 and 4 were given free uricase or UOXLVs intravenously at the same enzyme dose of $2 \mathrm{U} / \mathrm{kg}$, which differed from the rats in Group 2.

Blood samples (about $500 \mu \mathrm{L}$ ) were drawn from the posterior orbital venous plexus at indicated times $(3,5,7,9$, and 12 hours) and incubated at $37^{\circ} \mathrm{C}$ for 20 minutes. Next, the blood samples were centrifuged at $3000 \mathrm{rpm}$ for 10 minutes and the uric acid in the plasma was measured using Uric Acid Assay Kit (C012) (Nanjing Jiancheng Bioengineering Institute, Nanjing, China). An indirect equilibrium method - spectrophotometric detection at $690 \mathrm{~nm}$ - was used to determine the uric acid level. ${ }^{22}$ This method was based on the reduction of phosphor-tungstic acid by uric acid to give tungsten blue in an alkaline environment. Briefly, $0.2 \mathrm{~mL}$ of the sample was taken as the test, $2.0 \mathrm{~mL}$ of tungstic acid protein precipitating agent was added, and this was mixed well on a vortex mixer. After 10 minutes, the mixture was centrifuged at $3500 \mathrm{rpm}$ for 5 minutes. Next, $1.6 \mathrm{~mL}$ of the supernatant solution, $0.5 \mathrm{~mL}$ of the sodium carbonate-ureatriethanolamine reagent, and $0.5 \mathrm{~mL}$ of tungstophosphoric acid were added to the mixture and mixed for 10 minutes. The supernatant fluid was then pipetted into glass cuvettes. The absorbance at $690 \mathrm{~nm}$ wavelength was read against the distilled water. The plasma uric acid concentration of the sample was calculated as follows (Equation 2):

$$
\begin{aligned}
& \text { Serum uric acid }(\mu \mathrm{mol} / \mathrm{L}) \\
& =\frac{\mathrm{OD}_{\text {assay }}}{\mathrm{OD}_{\text {control }}} \times \text { Standard concentration }(297.4 \mu \mathrm{mol} / \mathrm{L})
\end{aligned}
$$

\section{Immunological test}

Antisera were prepared against the free uricase and UOXLVs in male Sprague Dawley rats. Free uricase $(250 \mu \mathrm{g})$ with $0.5 \mathrm{~mL}$ of blank lipid vesicles (used as an immunological adjuvant ${ }^{23}$ or UOXLVs (containing the equivalent dose of uricase) were multipoint injected into the rats subcutaneously. ${ }^{24}$ The rats were boosted every 2 weeks for 6 weeks with the corresponding antigen. Blood was collected prior to the first injection and on day 7 after the last injection. It was then centrifuged at $3500 \mathrm{rpm}$ for 10 minutes. The separated sera were stored at $-20^{\circ} \mathrm{C}$ until analysis.

An indirect enzyme-linked immune sorbent assay was developed to measure the anti-uricase antibodies. ${ }^{3}$ Microtiter plates (96 well) were coated with uricase (100 ng of protein per well) and stored at $4{ }^{\circ} \mathrm{C}$ overnight. The plates were then rinsed three times with PBST $(10 \mathrm{mM}$ phosphate-buffered saline [PBS], pH 7.4, and 0.5\% Tween [T]). Next, normal goat sera were applied to the wells for 2 hours. Six serial dilutions of the tested rat plasma samples were made in PBS and each dilution was analyzed in triplicate. The plates were incubated at $37^{\circ} \mathrm{C}$ with test sera for 2 hours and rinsed three times with PBST followed by incubation with $100 \mu \mathrm{L}$ of goat anti-rat IgG $(\mathrm{H}+\mathrm{L}) / \mathrm{HRP}$. The wells were then washed, as described. Next, a solution of $20 \mathrm{mM}$ orthophenylene diamine and $12 \mathrm{mM}$ hydrogen peroxide was added to the wells and the plates were incubated for 20 minutes at $37^{\circ} \mathrm{C}$. The color reaction was stopped by adding $2 \mathrm{~mol} / \mathrm{L}$ of sulfuric acid (containing $0.1 \mathrm{~mol} / \mathrm{L}$ of sodium sulfite). The absorbance of the wells was determined to be $490 \mathrm{~nm}$. The anti-uricase antibody titer was defined as the greatest dilution of the plasma, which resulted in an optical density that was 2.1 times higher than that of the negative control group. The negative control group was normal plasma (the rat was bled prior to the first injection) incubated with all reagents except for any potential primary antibody.

\section{Preliminary parenteral injection safety assessment}

For the hemolysis test, rabbit blood was used to test the hemolysis effect of the UOXLVs. Briefly, fresh rabbit blood was obtained from femoral arteria and the fibrinogen was removed by stirring with a glass rod. Physiological saline was added to the defibrinogen blood sample and the supernatant was removed through centrifugation at $3000 \mathrm{rpm}$ for 5 minutes. 
Erythrocyte pellets at the bottom of the centrifuge tube were washed four times (centrifugation followed by re-dispersion) with physiological saline. Finally, after repeated washing and centrifugation, an adequate amount of saline was added to the erythrocyte pellets to give a $2 \%$ erythrocyte standard dispersion that was stored at $4^{\circ} \mathrm{C}$. Different amounts of UOXLVs in volumes of $0,0.1,0.2,0.3,0.4$, and $0.5 \mathrm{~mL}$ were added to six tubes with $2.5 \mathrm{~mL}$ of $2 \%$ erythrocyte dispersion in each. Next, adequate amounts of physiological saline were added to every tube to obtain a final volume of $5 \mathrm{~mL}$. A positive control was prepared by adding $2.5 \mathrm{~mL}$ of water to $2.5 \mathrm{~mL}$ of $2 \%$ erythrocyte dispersion instead of physiological saline and UOXLVs. After vortex, the tubes were incubated at $37^{\circ} \mathrm{C}$ and observed microscopically from 15 minutes to 4 hours.

The stimulation test was conducted by administering $1 \mathrm{~mL}$ of UOXLVs to one side of the thigh quadriceps of the hind limbs of two rabbits. The thigh quadriceps of the two other sides of the hind limbs were injected with penicillin $G$ or physiologic saline at the same volume as the positive or negative control. At 48 hours postinjection, the rabbits were sacrificed by letting their blood, and the extent of the reaction in the thigh quadriceps was examined.

\section{Statistical analysis}

All data are shown as mean \pm standard deviation unless specifically outlined. One-way analysis of variance, Scheffe's F-test, and Student's $t$-test were used to statistically determine the significant differences in uric acid concentrations among different experimental groups. Statistical significance was established at $P<0.05$. Analyses were performed using the StatView statistical package (v 5.0; SAS Institute, Inc, Cary, NC). Pharmacokinetic analyses were undertaken using DAS software.

\section{Results \\ Preparation and characteristics of UOXLVs}

UOXLVs were successfully prepared using a reversephase evaporation method. The entrapment efficiency was $65.12 \% \pm 2.43 \%(n=3)$. The lipid vesicle size and polydispersity index were $201.54 \pm 7.10 \mathrm{~nm}(\mathrm{n}=3)$ and $0.14 \pm 0.03$ $(n=3)$, respectively. The zeta potential of the optimized formulation was $-34.10 \pm 4.18 \mathrm{mV},(n=3)$. Our results show that: (1) the activity of free uricase from $C$. utilis at physiological $\mathrm{pH}(82 \%)$ was lower compared with its maximum activity at optimal $\mathrm{pH}(100 \%),(2)$ the optimal $\mathrm{pH}$ and the maximum activity of uricase could be changed to 8.0 and $179.72 \%$ by entrapping the enzyme in the alkaline enzymosomes, and (3) the activity of the UOXLVs at physiological pH (178.26\%) was almost the same as at their optimum $\mathrm{pH}$. The optimum temperature of the UOXLVs $\left(40^{\circ} \mathrm{C}\right)$ was the same as that of the free uricase. The UOXLVs showed higher activity (from $169 \%$ to $195 \%$ ) than the free uricase (from $50 \%$ to $100 \%$ ) at temperatures from $30^{\circ} \mathrm{C}$ to $60^{\circ} \mathrm{C}$. These results are in accordance with previously reported results. ${ }^{15}$ Having improved the in vitro characteristics, the UOXLVs were subjected to further research.

\section{Enzyme kinetic estimation}

Kinetic constants $\left(\mathrm{K}_{\mathrm{m}}\right.$ and $\mathrm{V}_{\text {max }}$ ) were determined from a classic enzyme kinetic analysis based on the initial velocity measurements of the uric acid oxidation by either free uricase or UOXLVs at various uric acid concentrations $(10-50 \mu \mathrm{mol} / \mathrm{L})$. As shown in Figure 2, the kinetic data were fitted to the Lineweaver-Burk model and the results were expressed as follows:

$$
\begin{array}{cl}
\frac{1}{V}=0.0636 \cdot \frac{1}{[S]}+4.2218 & \mathrm{R}^{2}=0.9987 \text { (free uricase) } \\
\frac{1}{V}=0.046 \cdot \frac{1}{[S]}+3.3035 & \mathrm{R}^{2}=0.9723(\mathrm{UOXLVs})
\end{array}
$$

The mean values of the best-fit kinetic parameters of the Lineweaver-Burk model were estimated by linear regression as $\mathrm{K}_{\mathrm{m}}=15.07 \mu \mathrm{mol} / \mathrm{L}$ and $\mathrm{V}_{\max }=236.86 \mu \mathrm{mol} / \mathrm{s}$, and $\mathrm{K}_{\mathrm{m}}=13.93 \mu \mathrm{mol} / \mathrm{L}$ and $\mathrm{V}_{\text {max }}=302.71 \mu \mathrm{mol} / \mathrm{s}$ for free uricase and UOXLVs, respectively.

\section{Stability in the presence of plasma}

As shown in Figure 3, more than $95 \%$ of the original activity of the uricase in the lipid vesicles was sustained after 8 hours of incubation. In contrast, only about $70 \%$ of the activity from the free uricase was sustained at the identical time. The difference between the remaining activities of the UOXLVs and the free uricase was sig-

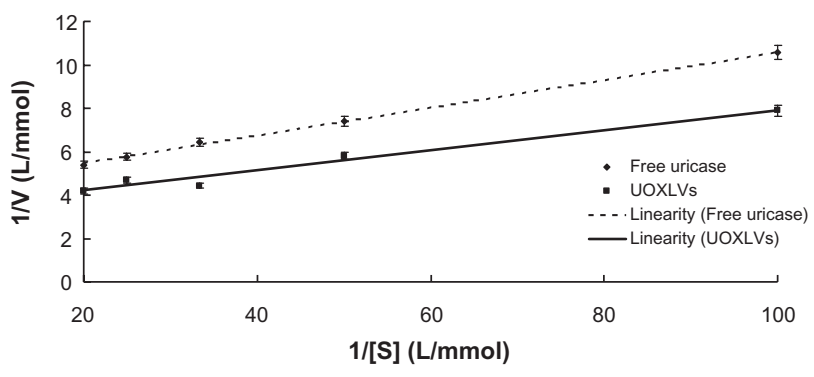

Figure 2 Lineweaver-Burk profiles of the uricase-containing lipid vesicles (UOXLVs) and free uricase $(n=3)$. 


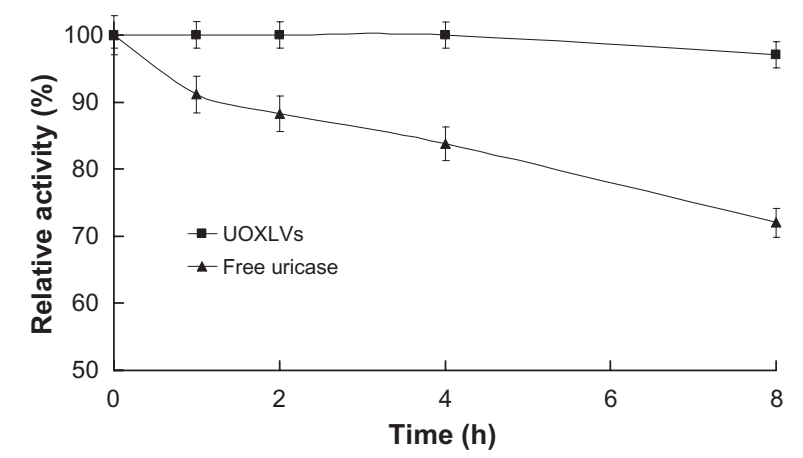

Figure 3 Time courses of the remaining activity of the uricase-containing lipid vesicles (UOXLVs) and free uricase in the presence of plasma (closed squares and triangles, respectively).

nificant $(P<0.01)$. The improved plasma stability was in agreement with published results, which state that lipid vesicles are helpful for improving enzyme stability in vitro and in vivo. ${ }^{15,16}$

\section{Pharmacokinetic study}

The pharmacokinetics of the UOXLVs and free uricase were compared following intravenous injection. The enzyme activity was much higher in the rats injected with UOXLVs than in those injected with free uricase at every corresponding time point. This phenomenon (higher activity for UOXLVs versus lower activity for free uricase) was in agreement with results observed in vitro. ${ }^{16}$ Furthermore, enzyme activity was maintained for a significantly longer time $(P<0.01)$ in the rats injected with UOXLVs compared with those injected with free uricase (Figure 4). Table 1 compares the pharmacokinetic parameters of the UOXLVs with those of free uricase, as estimated by statistical moment analysis.

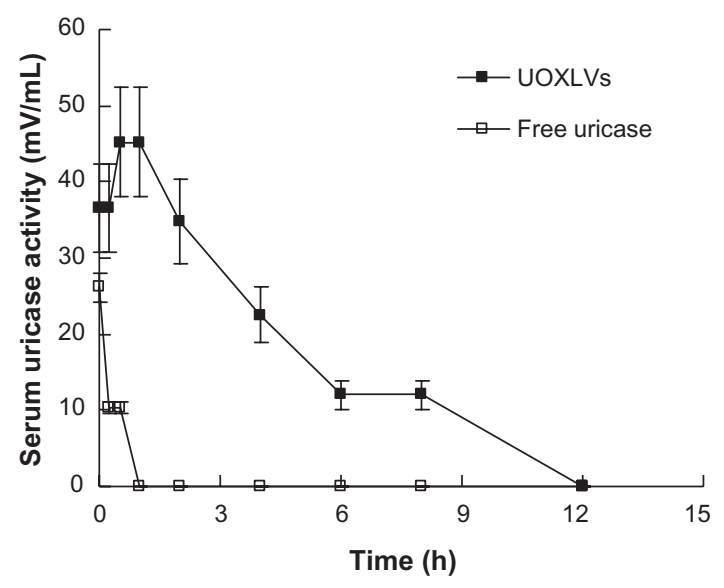

Figure 4 Plasma uricase activity versus time profiles after intravenous administration of uricase-containing lipid vesicles (UOXLVs) (closed squares) and free uricase (open squares) in rats.

Note: Each point represents the mean \pm standard deviation $(n=6)$.
Table I Pharmacokinetic parameters of uricase-containing lipid vesicles (UOXLVs) and free uricase in rats using a modelindependent approach

\begin{tabular}{lcc}
\hline Parameter & UOXLVs** & Free uricase \\
\hline $\mathrm{AUC}_{0-\mathrm{t}}(\mathrm{mU} \mathrm{h} / \mathrm{mL})$ & $221.63 \pm 21.5$ & $10.10 \pm 0.75$ \\
$\mathrm{AUC}_{0-\infty}(\mathrm{mU} \mathrm{h} / \mathrm{mL})$ & $227.60 \pm 25.3$ & $10.10 \pm 0.75$ \\
$\mathrm{MRT}_{0-\mathrm{t}}(\mathrm{h})$ & $3.45 \pm 0.17$ & $0.55 \pm 0.04$ \\
$\mathrm{MRT}_{0-\infty}(\mathrm{h})$ & $3.93 \pm 1.06$ & $0.55 \pm 0.04$ \\
$\mathrm{C}_{\text {max }}(\mathrm{mU} / \mathrm{mL})$ & $45.40 \pm 3.44$ & $26.10 \pm 2.7$ \\
$\mathrm{~T}_{\text {max }}(\mathrm{h})$ & $0.50 \pm 0$ & $0.017 \pm 0$ \\
$\mathrm{t}_{\mathrm{l} / 2}(\mathrm{~h})$ & $2.79 \pm 0.29$ & $0.38 \pm 0.03$ \\
$\mathrm{~V}(\mathrm{~mL} / \mathrm{kg})$ & $44.04 \pm 2.79$ & $76.64 \pm \mathrm{l} .50$ \\
$\mathrm{CL}(\mathrm{mL} / \mathrm{h} / \mathrm{kg})$ & $9.02 \pm 0.87$ & $198.02 \pm 14.01$ \\
\hline
\end{tabular}

Notes: Data represent mean value \pm standard deviation, $\mathrm{n}=6 ; * * p<0.01$, compared with free uricase.

Abbreviations: AUC, area under the plasma concentration-time curve; MRT, mean residence time; $C_{\max }$, maximum concentration; $T_{\max }$, peak time; $t_{1 / 2}$, half-life; $\mathrm{V}$, apparent volume of distribution; $\mathrm{CL}$, clearance.

\section{Pharmacodynamic study}

The effects of the UOXLVs and free uricase on circulating levels of uric acid were determined by quantifying the amount of uric acid remaining in the plasma of hyperuricemia rats at various times following injection of $2000 \mathrm{mU} / \mathrm{kg}$ of UOXLVs or uricase. As shown in Figure 5, the blood uric acid level was much lower in rats injected with UOXLVs than in those injected with free uricase at each time point $(P<0.01)$. Nevertheless, the blood uric acid levels of the UOXLV group and the free uricase group were lower than those of the hyperuricemia group $(P<0.01)$. The administration of UOXLVs resulted in a rapid lowering of plasma uric acid level from a high concentration $(444.21 \pm 32.34 \mu \mathrm{mol} / \mathrm{L})$ to $240 \mu \mathrm{mol} / \mathrm{L}$ (the normal uric acid level in human) within 3 hours, which was almost half the time necessary for the free uricase group (6 hours). The lowest uric acid level (48.43 $\pm 13.13 \mu \mathrm{mol} / \mathrm{L})$ was achieved at 12 hours after the intravenous injection of UOXLVs (compared with $162.7 \pm 39.23 \mu \mathrm{mol} / \mathrm{L}$ in the free uricase

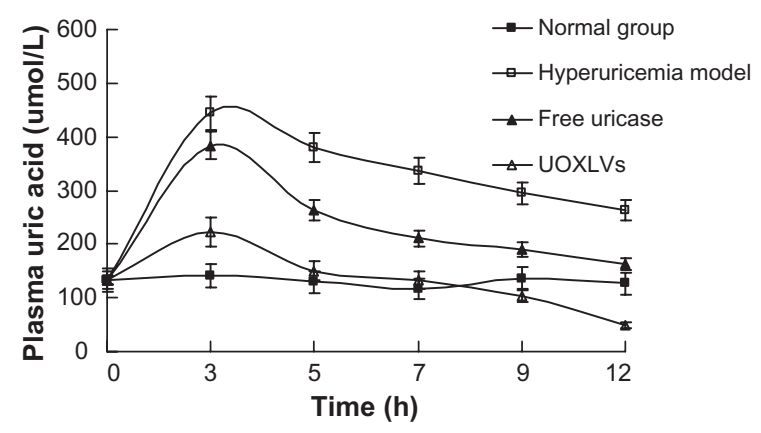

Figure $\mathbf{5}$ The plasma uric acid concentration versus time profiles after intravenous injection of the solvent (normal group, closed squares), hypoxanthine and oxonic acid (hyperuricemia model group, open squares), free uricase (closed triangles), and uricase-containing lipid vesicles (UOXLVs) (open triangles) in rats. The plasma uric acid concentration was determined by uric acid assay kit.

Note: Data are expressed as mean \pm standard deviation $(n=6)$. 
group, $263.73 \pm 18.91 \mu \mathrm{mol} / \mathrm{L}$ in the hyperuricemia model group, and $126.48 \pm 53.16 \mu \mathrm{mol} / \mathrm{L}$ in the normal group). In vivo pharmacodynamic studies explicitly suggest that UOXLVs decreased uric acid levels in the hyperuricemia rat model group. Therefore, compared with free uricase, the superior bioavailability and therapeutic efficacy of the UOXLVs was evident.

\section{Immunological test}

As the uricase in this study was a microbial enzyme (being from C. utilis), it was highly immunogenic; therefore, the immunogenicity of the UOXLVs was evaluated and compared with that of the free uricase. To determine if the lipid vesicles would inhibit the immunogenicity of the uricase, the UOXLVs were tested for their ability to induce an immune response, which provided evidence for the production of an anti-uricase antibody. In these experiments, mice were subcutaneously injected every 2 weeks for 6 weeks and the production of antibodies was determined through the enzyme-linked immune sorbent assay method. The working titer was defined as the greatest dilution of the plasma, which resulted in an optical density (at $450 \mathrm{~nm}$ ) that was 2.1 times higher than that of the negative control. As shown in Figure 6, the difference between the anti-uricase antibody titer of the UOXLVs and the free uricase was statistically significant $(P<0.01)$. As anticipated, the uricase was immunogenic in rats, whereas the UOXLVs were weakly immunogenic. This suggests that immunogenicity was reduced by entrapping uricase in the novel alkaline enzymosomes and the reduction of immunogenicity was favorable for the utilization of an enzyme as a therapeutic agent.

\section{Preliminary toxicity}

During the pharmacodynamic and pharmacokinetic experimental period, the UOXLVs were well tolerated by all animals. No obvious functional changes or signs of toxicity were observed and all the animals survived. It is speculated that the safety level of this technique may be due to the low toxicity of uricase and the biodegradable properties of the lipid used. Good biocompatibility and the lack of toxicity of lipid vesicles have already been confirmed. ${ }^{25}$

\section{Hemolysis test and stimulation test}

Complete hemolysis was observed in the positive control tube at 15 minutes: the solution was red, clearly diaphanous, and no erythrocytes survived at the bottom of the tube. The erythrocytes precipitated at the bottom of the other six tubes and dispersed after shaking, and the supernatant was achromatic and transparent in the observation period for 4 hours. These results demonstrate that UOXLVs do not cause hematolysis and erythrocyte agglutination at $37^{\circ} \mathrm{C}$. In the stimulation test, there was no notable difference between the rabbits' muscles after injection with UOXLVs or physiologic saline (negative control group). Neither hyperemia nor necrosis was observed in the rabbits' muscles after injection with UOXLVs or physiologic saline. These results demonstrate that UOXLVs are suitable for injection-based administration.

\section{Discussion}

Native uricase or recombinant uricase from Candida spp. have been characterized by an alkaline optimal $\mathrm{pH}(8.5-$ 9.5). ${ }^{4,26}$ Fortunately, uricase from C. utilis can be efficiently encapsulated in the novel alkaline enzymosomes, which consequently changes the optimal $\mathrm{pH}$ and increases the
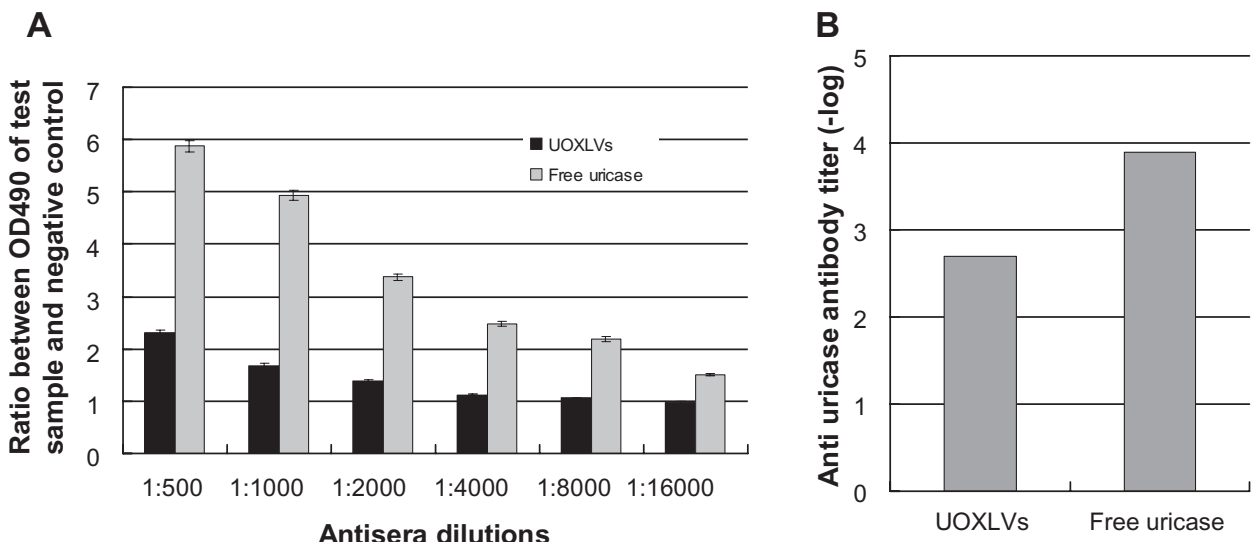

Figure 6 Immunogenicity test results. (A) Antisera dilution ratio; (B) antibody titer.

Note: The data represent the mean \pm standard deviation $(n=6)$.

Abbreviation: UOXLVs, uricase-containing lipid vesicles. 
catalytic activity. The uricolytic activity of the UOXLVs was about 2.2 times higher than that of the free uricase, and 3 higher than times that of PEGylated uricase (Puricase ${ }^{\circledR}$ [Savient Pharmaceuticals, East Brunswick, NJ], a new product $)^{27}$ under physiological $\mathrm{pH}$ and temperature in vitro. The shift of optimum $\mathrm{pH}$ and increased uricolytic activity of the UOXLVs suggest that some favorable conformation changes of uricase might occur during the entrapment process, although the mechanism is yet to be identified. UOXLVs may have other favorable in vitro and in vivo properties.

A slightly lower apparent $\mathrm{K}_{\mathrm{m}}$ value was obtained for the UOXLVs (7.56\% lower than that for the free enzyme), which indicates that uricase inside the lipid vesicle has a slightly higher affinity for the substrate. The decreased value of $\mathrm{K}_{\mathrm{m}}$ suggests that: (1) the favorable confirmation change of uricase might occur during the entrapment process (the shift of optimum $\mathrm{pH}$ and increased uricolytic activity also suggests a conformation change of the uricase during the entrapment process); (2) the affinity of the enzyme for the substrate may be strengthened by the charge effect or the hydrophobic interaction between the lipid vesicle and the uric acid; and (3) although the enzyme activity of the UOXLVs may be much higher than that of the free uricase, the concentration of the substrate in the core of the vesicles may be significantly lower than the temperature outside vesicles. This means that the two effects may cancel each other out and a relatively similar $\mathrm{K}_{\mathrm{m}}$ may be exhibited by the UOXLVs and the free uricase.

As we know, a lipid vesicle membrane (ie, the membrane of the UOXLVs) may be considered a semipermeable membrane as well as a selectively permeable membrane, a partially permeable membrane, or a differentially permeable membrane. A semipermeable membrane allows certain molecules and ions to pass through it by diffusion and, occasionally, by specialized facilitated diffusion. The rate of passage depends on the property and area of the membrane, the concentration of the substrate on either side and the property of the substrate. The semipermeable membrane is more permeable to drugs that are small, molecular, liposoluble, and low polar. The substrate's degree of dissociation has a significant effect on permeability. In general, the semipermeable membrane allows the molecular drug to pass through it freely, while the ionic drug is usually restricted to one side of the membrane. The Henderson-Hasselbalch equation can explain the relationship between the ionized and unionized species of a weak acid (or a weak base). In our study, the membrane of the UOXLVs was impermeable to the large enzyme molecule (Mw: $124 \mathrm{KD}$ ). However, the substrate of uricase (uric acid) was a small molecule (Mw: 168.10) and liposoluble (very slightly soluble, solubility was $0.13 \mathrm{mg} / \mathrm{mL}$, and the oil-water partition coefficient was -2.67). The uric acid was able to permeate the lipid vesicle membrane because the uric acid concentration outside the membrane was much higher than the concentration inside the membrane, which allowed the uric acid to enter into the semipermeable membrane.

A similar phenomenon occurred in the case of allantoin. This catalysate was also a small molecule (Mw: 158.12) with a degree of liposolubility (the water solubility was $0.6 \%$ and the oil-water partition coefficient was -2.89). Although the kinetics of uric acid into the lipid vesicle membrane of the UOXLVs and allantoin outside the membrane are still not clear, the uricase kinetic results suggest a comprehensive relationship between the enzyme, substrate, and catalysate. A similar result has been reported for amyloglucosidase entrapped in dipalmitoylphosphatidylcholine multi-lamellar lipid vesicles $\left(\mathrm{K}_{\mathrm{m}(\mathrm{app})}=6.39 \mathrm{mmol} / \mathrm{L}\right.$ versus $\mathrm{K}_{\mathrm{m}}=8.61 \mu \mathrm{mol} / \mathrm{L}$ for the free enzyme). ${ }^{10}$

In contrast, the apparent $\mathrm{K}_{\mathrm{m}}\left(\mathrm{K}_{\mathrm{m}(\mathrm{app})}\right)$ has been reported as being higher when immobilizing uricase on carboxymethyl high amylase starch cross-linked $35\left(\mathrm{~K}_{\mathrm{m}(\mathrm{app})}=170 \mu \mathrm{mol} / \mathrm{L}\right.$ versus $\mathrm{K}_{\mathrm{m}}=30 \mu \mathrm{mol} / \mathrm{L}$ for the free enzyme), which suggests an apparent decrease in the affinity of the enzyme in the urate substrate for the enzyme conjugation (probably due to the gel diffusion barrier). ${ }^{26}$ Moreover, in previous reports, the $\mathrm{K}_{\mathrm{m}}$ for the free uricase from C. utilis was $15.07 \mu \mathrm{mol} / \mathrm{L}$, while the $\mathrm{K}_{\mathrm{m}}$ for the native uricase from C. utilis was $20 \mu \mathrm{mol} / \mathrm{L}^{3}$ and $30 \mu \mathrm{mol} / \mathrm{L},{ }^{28}$ and the $\mathrm{K}_{\mathrm{m}}$ for the recombinant uricase from C. utilis, $54 \mu \mathrm{mol} / \mathrm{L}$. ${ }^{4}$ The change in $\mathrm{K}_{\mathrm{m}}$ for the native uricase may be due to difference in the determination method (oximetric versus spectrophotometrical methods), medium $\mathrm{pH}$, buffer type, and/or enzyme producer.

In this study, improved pharmacokinetic properties were observed in the UOXLVs when compared with the free uricase. When an identical dose of uricase formulated in enzymosomes was administered to rats, the elevated plasma uricase activity level was maintained for up to 12 hours. The maximum plasma level of uricase obtained was $45.40 \pm 3.44 \mathrm{mU} / \mathrm{mL}$ for the UOXLVs versus $26.1 \pm 5.7 \mathrm{mU} / \mathrm{mL}$ for the free uricase, and the terminal half-life of the uricase in enzymosomes increased to $2.79 \pm 0.29$ hours versus $0.38 \pm 0.03$ hours for the free uricase. Similarly, a longer

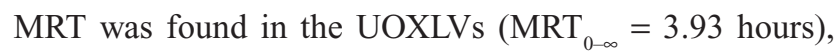
while the MRT in the free uricase was 0.55 hours. Therefore, it can be assumed that the uricase was protected by the lipid membrane of the enzymosomes from possible proteolytic 
degradation and phagocytic clearance, and the favorable structural and functional integrity of the loaded uricase and the enzymosomes might be reserved. Furthermore, the values of the AUC versus the UOXLV time curve $(221.63 \pm 21.50 \mathrm{mU}$ hour $/ \mathrm{mL}$ ) were about 22 -fold higher than those of the free uricase. It should be noted that the maximum plasma level of the uricase in UOXLVs was obtained at 30 minutes instead of at the beginning ( 0 minutes) and the mechanism of this phenomenon is still unclear.

Additionally, the maximum activity value for the free uricase $(26.1 \pm 5.7 \mathrm{mU} / \mathrm{mL})$ was only equal to $57.49 \%$ of that of the UOXLVs $(45.40 \pm 3.44 \mathrm{mU} / \mathrm{mL})$. The plasma uricase activity level decreased distinctly in the free uricase group (about $10 \mathrm{mU} / \mathrm{mL}$ after 0.25 hours to below the detection limit after 1 hour) and the terminal half-life was $0.38 \pm 0.03$ hours. The rapid drop in uricase activity might be due to the fast elimination and/or deactivation of the uricase. The half-life of the free uricase has been documented at $0.6^{6}$ and 1 hour, ${ }^{29}$ and $3^{30}$ and 6.5 hours, ${ }^{31}$ which differ from that obtained in the current study ( 0.38 of an hour). The change in the plasma circulating time may be due to the difference in the uricase source, the animal species and weight, the dose administered, and/or the test conditions. In short, the enzymosomes had a significant advantage in terms of the favorable pharmacokinetic behavior of the uricase, compared with the free uricase. The prolonged terminal half-life of the uricase observed in the lipid vesicles is consistent with previous reports on enzyme, ${ }^{13}$ protein, ${ }^{32}$ and nucleoside drugs. ${ }^{33}$

To decrease the plasma uric acid levels to as low as possible to thus achieve a better enzyme-replacement therapy effect, uricase requires an adequate blood enzyme level and high enzyme activity over a prolonged period. This was not attainable for free uricase due to the low uricolytic activity, short half-life, and rapid elimination from the plasma under the physiological conditions. It was encouraging to see that higher uricolytic activity, a longer half-life, and slower elimination of uricase could be realized by encapsulating the uricase in enzymosomes. The favorable conformation changes might result in an enhanced catalyzing function change; however, the retarded release of uricase from UOXLVs resulted in prolonged circulation time, catalyzing time, and improved therapy efficacy. The administration of UOXLVs resulted in the rapid and sustained lowering of plasma uric acid in the hyperuricemic rats.

The immunological test results indicated that the UOXLVs greatly decreased the immunogenicity of the uricase. No stimulation, erythrocatalysis, or agglomeration was observed for the UOXLVs in rabbits, which further indicates their safety.

\section{Conclusion}

In this study, innovative alkaline uricase enzymosomes were successfully developed to improve the biological properties and hyperuricemia effect of uricase from C. utilis. Theoretically, the increased in vivo uricolytic activity is of great clinical significance because the clinical dosage and the side effects were greatly reduced. Furthermore, our experimental results confirm that the immunogenicity of UOXLVs is much less than that of the free uricase. Moreover, a preliminary parenteral injection safety assessment showed that the safety of UOXLVs was acceptable. Therefore, UOXLVs might be a preferred alternative treatment to cure hyperuricemia and gout.

\section{Acknowledgments}

The authors thank Professor F Liao, B Lu, and X Yang for their helpful discussions and comments pertaining to this project. This research was partially supported by grants from the National Natural Science Foundation of China (No 30973645), the Chongqing Natural Science Foundation (CSCT2012 JJB10027), and the Chongqing Education Committee Fund (the Excellent University Personnel Financial Aid Plan, KJ120321).

\section{Disclosure}

The authors report no conflicts of interest in this work.

\section{References}

1. Saeed HM, Abdel-Fattah YR, Gohar YM, Elbaz MA. Purification and characterization of extracellular Pseudomonas aeruginosa urate oxidase enzyme. Pol J Microbiol. 2004;53:45-52.

2. Pasut G, Sergi M, Veronese FM. Anti-cancer PEG-enzymes: 30 years old, but still a current approach. Adv Drug Deliv Rev. 2008;60: 69-78.

3. Bomalaski JS, Holtsberg FW, Ensor CM, Clark MA. Uricase formulated with polyethylene glycol (uricase-PEG 20): biochemical rationale and preclinical studies. J Rheumatol. 2002;29:1942-1949.

4. Freitas DS, Spencer PJ, Vassao RC, Abrahao-Neto J. Biochemical and biopharmaceutical properties of PEGylated uricase. Int J Pharm. 2010; 387:215-222.

5. O’Loughlin JA, Bruder JM, Lysaght MJ. Degradation of low molecular weight uremic solutes by oral delivery of encapsulated enzymes. ASAIOJ. 2004;50:253-260.

6. Yasuda Y, Fujita T, Takakura Y, Hashida M, Sezaki H. Biochemical and biopharmaceutical properties of macromolecular conjugates of uricase with dextran and polyethylene glycol. Chem Pharm Bull. 1990;38: 2053-2056.

7. Magnani M, Mancini U, Bianchi M, Fazi A. Comparison of uricase-bound and uricase-loaded erythrocytes as bioreactors for uric acid degradation. Adv Exp Med Biol. 1992;326:189-194.

8. Sessa G, Weissmann G. Incorporation of lysozyme into liposomes. A model for structure-linked latency. J Biol Chem. 1970;245: 3295-3301. 
9. Eugenia M, Cruz M, Gaspar MM, Barbara M, Martins F, Corvo ML. Liposomal superoxide dismutases and their use in the treatment of experimental arthritis. In: Nejat D, editor. Methods in Enzymology, Liposomes. London: Academic Press. 2005;391:395-413.

10. Li M, Hanford MJ, Kim JW, Peeples TL. Amyloglucosidase enzymatic reactivity inside lipid vesicles. J Biol Eng. 2007;1:4.

11. Budai M, Chapela P, Gróf P, et al. Physicochemical characterization of stealth liposomes encapsulating an organophosphate hydrolyzing enzyme. J Liposome Res. 2009;19:163-168.

12. Tan Q, Zhang J, Zhang L. Not only anticancer drugs but also enzymes can be encapsulated in either micelle or other carrier for the treatment of cancer. Med Hypotheses. 2010;74:396-397.

13. Walde P, Ichikawa S. Enzymes inside lipid vesicles: preparation, reactivity and applications. Biomol Eng. 2001;18:143-177.

14. Yoshimoto M. Stabilization of enzymes through encapsulation in liposomes. Methods Mol Biol. 2001;679:9-18.

15. Tan QY, Wang N, Yang H, et al. Characterization, stabilization and activity of uricase loaded in lipid vesicles. Int J Pharm. 2010;384: 165-172.

16. Tan QY, Wang N, Yang H, et al. Preparation and characterization of lipid vesicles containing uricase. Drug Deliver. 2010;17:28-37.

17. Tiourina $\mathrm{O}$, Sharf T, Balkina A, et al. Interaction of the water-soluble protein aprotinin with liposomes: gel-filtration, turbidity studies, and 31P NMR studies. Liposome Res. 2003;13:213-229.

18. Georgiou CD, Grintzalis K, Zervoudakis G, Papapostolou I. Mechanism of Coomassie brilliant blue G-250 binding to proteins: a hydrophobic assay for nanogram quantities of proteins. Anal Bioanal Chem. 2008; 391:391-403.

19. Zhang JQ, Zhang ZR, Yang H, Tan QY, Qin SR, Qiu XL. Lyophilized paclitaxel magnetoliposomes as a potential drug delivery system for breast carcinoma via parenteral administration: in vitro and in vivo studies. Pharm Res. 2005;22:573-583.

20. Zhao Y, Zhao L, Yang G, Tao J, Bu Y, Liao F. Characterization of a uricase from Bacillus fastidious A.T.C.C. 26904 and its application to serum uric acid assay by a patented kinetic uricase method. Biotechnol Appl Biochem. 2006;45:75-80.

21. Huisinga W, Telgmann R, Wulkow M. The virtual laboratory approach to pharmacokinetics: design principles and concepts. Drug Discov Today. 2006;11:800-805.
22. Zhang C, Yang XL, Feng J, et al. Effects of modification of amino groups with poly(ethylene glycol) on a recombinant uricase from Bacillus fastidiosus. Biosci Biotechnol Biochem. 2010;74:1298-1301.

23. Allison AG, Gregoriadis G. Liposomes as immunological adjuvants. Nature. 1974;252:252.

24. Rongen HAH, Bult A, Van BWP. Liposomes and immunoassays. J Immunol Methods. 1997;204:105-133.

25. Lasic DD. Novel applications of liposomes. Trends Biotechnol. 1998;16: 307-321.

26. Sherman MR, Saifer MG, Williams LD, inventors; Mountain View Pharmaceuticals, Inc, assignee. Aggregate-free urate oxidase for preparation of non-immunogenic polymer con-immunogenic polymer conjugates. United States patent US 6783965 B1. August 31, 2004.

27. Kaye SB. Liposomes - Problems and promise as selective drug carriers. Cancer Treat Rev. 1981;8:27-50.

28. Mulhbacher J, McGeeney K, Ispas-Szabo P, Lenaerts V, Mateescu MA. Modified high amylose starch for immobilization of uricase for therapeutic application. Biotechnol Appl Biochem. 2002;36:163-170.

29. Nishimura H, Matsushima A, Inada Y. Improved modification of yeast uricase with polyethylene glycol, accompanied with nonimmunoreactivity towards anti-uricase serum and high enzymic activity. Enzyme. 1981;26:49-53.

30. Chen RH, Abuchowski A, Van ET, Palczuk NC, Davis FF. Properties of two urate oxidases modified by the covalent attachment of poly(ethylene glycol). Biochim Biophys Acta. 1981;660:293-298.

31. Schiavon O, Caliceti P, Ferruti P, Veronese FM. Therapeutic proteins: a comparison of chemical and biological properties of uricase conjugated to linear or branched poly(ethylene glycol) and poly(N-acryloylmorpholine). Farmaco. 2000;55:264-269.

32. Constantinides PP, Chaubal MV, Shorr R. Advances in lipid nanodispersions for parenteral drug delivery and targeting. Adv Drug Deliv Rev. 2008;60:757-767.

33. Garg M, Dutta T, Jain NK. Reduced hepatic toxicity enhanced cellular uptake and altered pharmacokinetics of stavudine loaded galactosylated liposomes. Eur J Pharm Biopharm. 2007;67:76-85.
International Journal of Nanomedicine

\section{Publish your work in this journal}

The International Journal of Nanomedicine is an international, peerreviewed journal focusing on the application of nanotechnology in diagnostics, therapeutics, and drug delivery systems throughout the biomedical field. This journal is indexed on PubMed Central, MedLine, CAS, SciSearch $\AA$, Current Contents ${ }^{\circledR} /$ Clinical Medicine,

\section{Dovepress}

Journal Citation Reports/Science Edition, EMBase, Scopus and the Elsevier Bibliographic databases. The manuscript management system is completely online and includes a very quick and fair peer-review system, which is all easy to use. Visit http://www.dovepress.com/ testimonials.php to read real quotes from published authors. 